\title{
Loiolaetxea: respuesta a la exclusión desde la solidaridad
}

\author{
Ane Ferran Zubillaga \\ Departamento de Trabajo Social y Sociología, Universidad de Deusto \\ <aferran@deusto.es>
}

\begin{abstract}
Loiolaetxea, Jesusen Lagundiak Donostian duen egoitza zentro bat da, eta bertan hartzen ditu preso, bazterkeria pairatzeko arrisku edo egoera horretan dauden pertsonak. Bazterkeriaren arreta sarean kokatzen da, Gipuzkoako Foru Aldundiaren zentro laguntzailea delako. Ondorengo artikuluak Loiolaetxea proiektuaren elementu nagusiak azaltzen ditu, hala nola, pertsona zaurgarrienekin errotze mekanismoak lantzearen aukera, beti ere, garapen pertsonalerako prozesu integralen lagun egitean oinarrituak. Bere proiektua eredu komunitarioan kokatzen da, eguneroko bizitzan gauzatzen dena. Halaber, fedea eta justizia lotzeko duen euskarriari lotuta, Loiolaetxeak pertsonaren espiritualtasunaren dimentsioa ere lantzen du.
\end{abstract}

\section{GAKO-HITZAK:}

Lagun egitea, espiritualitatea, gizarteratzea, hirugarren sektorea, politika publikoak, Gipuzkoa.
Loiolaetxea es un centro residencial de la Compañía de Jesús ubicado en San Sebastián (Gipuzkoa), donde se acoge a personas que están presas y a personas en riesgo o situación de exclusión. Forma parte de la red de atención a la exclusión y es un centro colaborador de la Diputación Foral de Gipuzkoa. El presente artículo narra los elementos clave del proyecto de Loiolaetxea y su opción por trabajar los mecanismos de arraigo con las personas más vulnerables; siempre desde el acompañamiento de procesos integrales de desarrollo personalizado. Su proyecto se engarza en el modelo comunitario, enmarcado en la vida cotidiana. Igualmente y a partir de la opción de Loiolaetxea por vincular fe y justicia, el proyecto aborda, también, la dimensión espiritual de las personas.

\section{PALABRAS ClaVe:}

Acompañamiento, espiritualidad, inclusión, tercer sector políticas públicas, Gipuzkoa. 


\section{Introducción}

Loiolaetxea es un centro residencial de titularidad privada, enmarcado en la red pública de atención a la inclusión social en Gipuzkoa. Como tal, acoge a personas que están presas en diversos centros penitenciarios de la comunidad autónoma (principalmente en el de Martutene, en San Sebastián) y a personas en riesgo o situación de exclusión que han sido valoradas por el Servicio de Protección a la Mujer Víctima de Violencia Machista y de Inclusión Social de la Dirección General de Protección a la Infancia y de la Inclusión Social, encuadrado, a su vez, en el Departamento de Políticas Sociales de la Diputación Foral de Gipuzkoa. Dispone de diez plazas concertadas en el marco de un convenio de colaboración firmado por ambas entidades en 2004. Se trata, por tanto, de un centro de titularidad privada que gestiona plazas públicas. Además, y atendiendo a la especificidad de los procesos de intervención y los procedimientos de actuación de Instituciones Penitenciarias, dispone de tres plazas más, fuera del convenio con Diputación, que le permiten responder con agilidad a las solicitudes, a veces inmediatas, de Instituciones Penitenciarias.

El presente artículo es parte de la tesis doctoral dirigida por el profesor Jon Leonardo, catedrático de la Universidad de Deusto, y defendida en diciembre de 2016. La tesis analiza el papel de las organizaciones de iniciativa social en la atención residencial a las personas en riesgo 0 situación de exclusión en el marco de la política social guipuzcoana, a partir del análisis del caso de Loiolaetxea. La investigación realizada ha querido entablar una "conversación reflexiva con una situación concreta” (Schön, 1998: 248), la de Loiolaetxea. Una conversación que inició ella misma con la Universidad de Deusto, buscando argumentos que contextualizaran y consolidaran su opción por pertenecer a la red de recursos y servicios de la política social guipuzcoana. Una conversación pausada y profunda que hemos intentado contextualizar en un marco general que le diera sentido y que permitiera 'ver el bosque', evitando caer en la miopía del caso particular.

Lo que exponemos a continuación es un resumen del análisis referido a la experiencia de Loiolaetxea, desde las percepciones y opiniones de las personas que constituyen sus grupos de interés. Así, la investigación se ha basado en el análisis cualitativo de 34 entrevistas en profundidad ${ }^{1}$ realizadas a personas de la administración guipuzcoana (foral y local), de Instituciones Penitenciarias, de entidades que conforman junto con ella la red de atención, a expertos en el sector y a miembros del equipo de Loiolaetxea.

${ }^{1}$ En las citas aportadas en este texto, se utiliza la siguiente codificación para identificar el ámbito al que pertenece la persona que aporta la cita: C: experto del ámbito del conocimiento; P: responsable político; T: técnico del ámbito público; S: tercer sector; L: Loiolaetxea; R: residente.
Queremos hacer una mención especial a las personas residentes de Loiolaetxea (actuales y pasadas) que se han ofrecido a participar en esta investigación. Su aportación es clave para valorar el conjunto, porque, siguiendo con el símil del bosque, esta investigación ha querido valorar 'un árbol concreto' en el conjunto del bosque, y para ello, sus voces son indispensables.

\section{Loiolaetxea: una opción por trabajar los mecanismos de arraigo con las personas más vulnerables.}

\subsection{El perfil de las personas residentes y su importancia en la red}

Tal y como se ha dicho, Loiolaetxea es un recurso de la red guipuzcoana de inserción social, preferentemente para personas que tienen experiencia penitenciaria. Junto con Cruz Roja y Arrats, es la entidad que dirige su mirada a este colectivo en Gipuzkoa. Una mirada que está perfectamente identificada por todas las personas consultadas y que es muy bien valorada por la red y también por los propios internos del centro penitenciario de Martutene. Tanto unos como otros consideran que es el único centro para determinados perfiles:

Desde mi posición de prisión, creo que es un recurso necesario, porque cubre un espacio que no se cubre de otra manera para este perfil del que te hablo. Creo que tiene que haber un recurso para estas personas que han tenido una ruptura y que han ingresado en prisión y que necesitan reconstruir toda su red ( $\left.\mathrm{S}_{5}: 9\right)$.

Porque Loiolaetxea es la única opción que hay para que personas extranjeras, como yo y mujer, pueda ir a ser insertada o tener un espacio que pueda estar planteando [la inserción] (R5: 1).

Esta opción preferencial por el colectivo con causas penales abiertas no le ha impedido que, tras una valoración de cuáles son las necesidades no cubiertas, atiendan también a otros perfiles. En cualquier caso, esta opción preferencial se constituye en una clara seña de identidad de este servicio por dos cuestiones. En primer lugar, porque es su primera aportación de valor reconocida por la red, tal y como recogemos en esta cita:

Sabes que es muy interesante el trabajo que hacen con la gente con experiencia penitenciaria. Porque ahí hay un agujero, y sobre todo hay un estigma social... Que haya habido ejemplos como Loiolaetxea y Arrats, que hayan conseguido dar respuesta a un colectivo. Que además socialmente es del colectivo de pobres no merecedores ( $\left.P_{4}: 67\right)$.

Y, en segundo lugar, porque ha optado por acoger a una tipología de personas que tienen una gran 
carencia afectivo/relacional y una necesidad de generar vínculos:

Hay perfiles que necesitan control, supervisión. 0 perfiles que necesitan, que tienen muchas carencias afectivas. Y necesitan tejer una vinculación muy sólida o muy constante. Esas personas, es mejor que vayan a Loiolaetxea, donde el apoyo, no ya tanto sólo por la supervisión, que también, sino por el acompañamiento afectivo, es mayor. La gente que arrastra una soledad muy fuerte, pues igual necesita un recurso más del estilo de Loiolaetxea (S5: 1).

Incluso aquellas personas que están en situación administrativa irregular (los que 'no tienen papeles'), personas pendientes siempre de las órdenes de expulsión, que pueden cortar en seco los procesos de inclusión, ellas y ellos también tienen sitio:

Hubo una época, hace años, [en] que Loiolaetxea acogía personas, no sólo en situación irregular: ¡estando en prisión en situación irregular! Con lo que eso conlleva a la hora de hacer un proceso de inserción: es muy complejo ( $\left.\mathrm{S}_{5}: 12\right)$.

Estamos, pues, ante un servicio que opta claramente por un colectivo de personas con una problemática concreta: la necesidad de trabajar los vínculos relacionales en situaciones claras de ruptura como la que provoca la prisión. Evidentemente, esta opción por acoger a personas con necesidades relacionales hace que aborde los mecanismos de arraigo, aquellos que tienen que ver con la existencia de vínculos sociales, comunitarios y familiares (Renes et al., 2007).

\subsection{Características estructurales de Loiolaetxea}

Los elementos estructurales característicos de Loiolaetxea ayudan a trabajar el arraigo. Se trata de una casa, con trece plazas disponibles, donde además, vive y convive una comunidad de jesuitas (actualmente compuesta por cuatro personas).

Una casa, que no es un piso ni un centro, y que le otorga una singularidad propia en la red. Está situada en el centro de Donostia, en las faldas del monte Ulía, en una calle discreta donde también se ubican dos colegios, una residencia de personas mayores y la sede central de Proyecto Hombre en Gipuzkoa.

La propia edificación y el número de las plazas son elementos muy bien valorados tanto por los profesionales de la red como por los propios residentes: una casa que, por su tamaño, permite cercanía y calidez, y que está bien situada en la ciudad.

La casa, el tamaño de la casa, dónde está ubicada: este tipo de elementos también favorecen que sea así. El número, claro; indudablemente, ¿no?: a mayor número de personas, pues más difícil es poder generar esto. El número, la localización también, la casa, también efectivamente [favorecen] la goxotasuna, la calidez (S4: 40).

Sin embargo, también hay voces que cuestionan que una casa de este tipo pueda ser considerada un centro y si cumpliría con los estándares de calidad que, aun no existiendo todavía en el sector, sí se dan en otros ámbitos:

Luego, la dimensión: tiene una dimensión que no es piso, pero tampoco es centro, ya de 20 plazas, 25; y tampoco es el piso, que puede quedar en 6 . Entonces, estos centros [...], pues han resbalado [...], porque tiene una dimensión que no encaja ni en uno ni en otro (T6: 19).

\section{Acompañando procesos integrales de desarrollo personalizado}

En este estudio, partimos de la consideración sostenida por Renes et al. (2007), quienes, siguiendo a Castel, entienden que la exclusión está provocada por la ruptura de dos mecanismos clave en la vida de las personas: los relativos al acceso a los derechos básicos y los relacionados con la necesidad de arraigo. Estos mismos autores señalan que los recursos necesarios para superar una $u$ otra ruptura no son idénticos y que, concretamente en los casos en los que se trate de restaurar el arraigo, hay que apoyarse en aspectos no convencionales. En este sentido, consideran que, para superar esta ruptura, hay que diseñar procesos de reconstrucción y de empoderamiento desde un abordaje que genere y fortalezca espacios de apoyo, enmarcados en procesos colectivos y en iniciativas sigulares, que situén a la persona en situación de exclusión, como participante y protagonista (ibídem: 20). En definitiva, y en palabras de Cáritas Española (2009), se trata de acompañar procesos integrales de desarrollo personalizado.

La Federación Sartu (2010), por su parte, identifica algunos elementos clave para que los itinerarios de inserción puedan tener éxito. Así, considera que los procesos deben ser personalizados; con una visión global, integral y gradual, que promueva la autonomía personal; además, su diseño debe ser coordinado con otros profesionales involucrados, evitando duplicidades e incompatibilidades; por último, entiende que es clave que los procesos sean normalizados y utilicen prioritariamente aquellos recursos existentes en el entorno. Veamos cómo se implementan estos elementos en el proceso concreto de Loiolaetxea, para analizar, a partir de ellos, los resultados de su acción.

\subsection{Procesos personalizados de atención}

El primero de los elementos que menciona la Federación Sartu es que los procesos de inserción 
deben ser personalizados, dado que es la propia persona excluida la protagonista y actora del proceso de cambio. Para ello, se abordan un conjunto de etapas (todas ellas relacionadas con el itinerario vital de la persona) que tienen por objetivo generar unas condiciones de acceso adecuadas que permitan que la persona vaya integrándose en la red y vaya iniciando un camino que posibilitará elaborar los planes individualizados de atención (PIA), claves para desplegar los recursos endógenos e ir adquiriendo pautas de normalidad. Vamos a verlo con un cierto detalle.

\subsubsection{Cómo llegan. Las vías de acceso}

Dos son dos las vías de acceso a Loiolaetxea: la primera está en manos de la Diputación, que es la institución que formalmente deriva al centro a personas en riesgo o situación de exclusión, que han sido identificadas desde el Sistema Vasco de Servicios Sociales. Se accede desde Portuenea, el servicio de apoyo a la valoración de la exclusión que gestiona la Fundación Emaús. Portuenea es un servicio residencial de corta estancia (dos o tres meses, prorrogables) donde, a partir de la observación de las personas acogidas, se determinan cuáles son sus necesidades de apoyo, sus capacidades y limitaciones, y se vinculan con los servicios y programas existentes en la red de atención secundaria, en un intento de adecuar los recursos a las personas. El centro propone al Servicio de Valoración de la Exclusión de la Diputación, competente en la materia, el recurso al que destinaría a la persona en cuestión; además propone el establecimiento del marco concreto que va a definir la naturaleza de la intervención. Los residentes que acuden a Loiolaetxea derivados desde Portuenea relatan lo siguiente:

Me mandaron ahí, a Pasajes, eso es, y ahí estuve, ahí, por tres meses haciendo, estudiando castellano en la EPA [educación para adultos] y me están también valorando si seguir yendo, también mirando la situación, también hasta que mi [sic] toca la salida, ir. Y ven que yo hago las cosas muy bien, sin ningún problema, porque había ahí varios centros; después, cuando cumpla los tres meses, ahí ellos mirarán los centros donde puedo corresponder para estar ahí. Entonces sí, Itziar, de Loiolaetxea, un día estuvo ahí, [para] hacerme una entrevista, también [para] preguntar la situación, y eso luego después ellos dicen que bueno, que me meterán en el destino de Loiolaetxea (R1: 1).

La segunda vía de acceso, la que hace referencia a la acogida de las personas que están en prisión, se da en el propio proceso de trabajo que Loiolaetxea tiene en el centro penitenciario de Martutene, aunque también es consecuencia de las acciones llevadas a cabo por otros profesionales externos que trabajan dentro de la prisión y, por supuesto, a instancias de Instituciones Penitenciarias, que es, en definitiva, quien firma los permisos penitenciarios necesarios para que las personas puedan salir del centro. Nos lo cuenta una de las residentes:

Entonces, los miércoles a la tarde hacíamos como convivencia, era como una sala parecida a ésta, y entonces ellos iban ahí y nos proponían actividades, pues, por ejemplo, hablábamos de temas de actualidad, o cómo te ha ido la semana, o cómo te ha ido el día; hacíamos un poquito en [sic] coloquio, terapias de relajación. jJo!, la verdad que se agradecía mucho, porque era como aire fresco, ¿no? [...] Luego, los jueves a la mañana también va el equipo técnico a Martutene y hace entrevistas individuales, en las que te pregunta, bueno, pues qué expectativas [tienes], por qué quieres salir, qué vas a hacer cuando salgas de la cárcel, tu familia, tus estudios, qué idea [tienes], o sea, un poco para ir haciendo tu perfil, para que ellos sepan qué es lo que tú quieres hacer cuando salgas, qué es lo prioritario para ti (R2: 4).

Ésta es una de las claves: el proceso de acompañamiento empieza antes de llegar al centro. En el caso de las personas derivadas de Portuenea, sirve para trabajar las expectativas y permite evaluar si Loiolaetxea es o no un servicio adecuado. De hecho, esta labor es reconocida tanto por las y los residentes como por las y los profesionales del sector. Curiosamente, los residentes que han pasado por Portuenea utilizan las mismas palabras para referirse al centro: lo autodenominan "el primer peldaño", el lugar donde "nos entrenan" para poder responder bien.

En el caso de las personas derivadas desde la prisión, este primer contacto que Loiolaetxea establece con todas aquellas que así lo desean es imprescindible y se vive como una buena práctica:

\section{El modelo de Loiolaetxea de trabajar con ellos desde que están dentro, creo que de alguna manera yo estoy por incorporar parte de sus buenas prácticas $\left(\mathrm{S}_{5}: 20\right)$.}

\subsubsection{Las expectativas de las y los residentes}

Las y los residentes consultados coinciden al señalar que Loiolaetxea supera las expectativas que tenían antes de ingresar: hablan de que no esperaban encontrar tanto respeto, autonomía, no sentirse juzgados, tanto apoyo... Sin embargo, una de las opiniones recogidas destaca la idea de que lo importante es poder salir de prisión:

Es que cuando tú sales de la cárcel y cualquier cosa que te encuentres es mejor, entonces tú no haces [el] ejercicio de que, no te creas expectativas, porque todo es mejor de lo que tú vas a pasar ahí. [En cualquier caso] para nada esperaba que fueran a respetar y tampoco esperaba encontrar la diversidad de personas [que encontré] ( $\left.R_{5}: 3\right)$. 
En el sector, se considera que este trabajo por analizar las expectativas y trabajarlas previamente con las personas es crucial para poder ubicar en un contexto real lo que Loiolaetxea puede y lo que no puede ofrecer. Lo vemos recogido, entre otras, en la siguiente opinión:

Normalmente solíamos ir acompañándoles a esa primera cita, donde ellos un poco explicaban lo que era todo su proyecto, donde contaban un poco lo que eran los objetivos de la casa [...]. Que me parecía algo muy interesante, porque normalmente no se suele hacer. Se valora desde fuera que, para una persona, es el centro más idóneo, dentro de los recursos que hay posibles para uno, y a veces sin ponerle ni siquiera la idea física, ¿no?, de cómo es. Pues bueno, les ubicaban allí, con lo que conlleva gente que pudiera cumplir sus expectativas y gente que de repente se encontraba con algo que no (S6: 9).

Precisamente, éste es un punto que puede generar fricciones en la red. Hay opiniones que cuestionan este modo de proceder en tanto consideran que los centros, aun teniendo opinión y criterio para argumentar la idoneidad o no del servicio para la persona concreta, o la idoneidad o no del momento vital del grupo que convive en el servicio, no pueden tener la capacidad de decisión para aceptar o no a las personas que han sido previamente valoradas por la Diputación. Se trata de opiniones de personas de las entidades que argumentan cuestiones relacionadas con la posibilidad de que se rompa el principio de justicia y de equidad.

\subsubsection{Personalización del plan. Principio de individualidad}

La consideración de las expectativas de las y los residentes sirve como primer hilo para la elaboración de los PIA, documentos que recogen los objetivos socioeducativos acordados entre la persona residente y el equipo técnico. Éstos están definidos en el Decreto Foral 5/2014, por el que se regula el procedimiento de acceso a los recursos de inclusión social de atención secundaria dependientes de la Diputación de Gipuzkoa, como herramienta que garantiza el principio de atención personalizada propio del Sistema Vasco de Servicios Sociales. Las y los residentes son muy conscientes de esta herramienta y saben de su valor:

Y cada uno tiene un PIA diferente, y eso para mí me parece muy importante también (R2: 36).

Igualmente, las y los profesionales consultados en el marco de esta investigación y que conocen la acción de Loiolaetxea destacan este elemento. Es otra de sus buenas prácticas o propuestas de valor:

El trabajo es súper súper personalizado, muy muy ajustado, desde mi punto de vista, a las necesidades. Se toman mucho tiempo en el conocimiento de la persona, se consensúa mucho, con las personas que están ahí, los objetivos de trabajo (T3: 40).

Un trabajo personalizado en el contexto de una intervención intensiva y generadora de vínculos que entiende que los fracasos son parte sustancial del proceso, por lo que consideran que trabajar las recaídas o retrocesos es una cuestión clave en cualquier proceso de inclusión:

Es el trabajar la recaída como parte del proceso. Y no como un motivo de castigo ni de expulsión. En Loiolaetxea sí que entendían estas recaídas, como parte del proceso. Y lo que se hacía era intensificar el trabajo, ver un poco lo que había pasado (S6: 16).

Estamos, por lo tanto, ante una entidad que asume la necesidad de elaborar planes individualizados antes incluso de que el propio sistema regulara esta cuestión con la referencia explícita a los PIA que se recoge en la legislación. Ya hace algunos años que Loiolaetxea tenía sus propios planes educativo-terapéuticos individualizados (PETI), que consistían en un documento que recogía los acuerdos alcanzados con las personas residentes y que servía de base tanto en lo que se denominaba la fase de diagnóstico social como en el establecimiento de los objetivos de intervención planteados y que iban a servir de guía de todo el proceso durante su estancia en la casa.

\subsection{Procesos graduales e integrales para generar vínculos}

El segundo aspecto que la Federación Sartu (2010) destaca para posibilitar el éxito de los procesos de inserción se refiere a su integralidad y gradualidad. El proceso de trabajo en Loiolaetxea es gradual. Como hemos visto, empieza en la fase de valoración o diagnóstico (anterior a la fase de residencia, que es la que estamos abordando en profundidad). Se basa en encuentros esporádicos que van aumentando en intensidad y tiempo: primero, para comer, conocerse y conocer la casa; luego, algún fin de semana para profundizar y ayudar a decidir conscientemente que se desea estar en Loiolaetxea.

Además de gradual, es integral. Como apuntaban Renes et al. (2007), las lógicas del acceso y del arraigo constituyen un 'sistema dialógico', por lo que es necesario combinarlas para ponerlas a dialogar. En Loiolaetxea, se estructura la intervención desde el vínculo, elemento imprescindible para trabajar el arraigo, pero con una mirada integral de la inclusión. Esta mirada integral es señalada y destacada por las personas del sector que tienen relación con Loiolaetxea, entendiendo que es una de sus aportaciones de valor y que tiene como eje principal la generación, construcción y mantenimiento de los vínculos. 
Bueno, nosotros siempre de Loiolaetxea el elemento que hemos destacado es la forma integral de trabajar los procesos (S6: 14).

Esta forma de abordar los procesos y generar vínculos trasciende a la propia fase de residencia. Las aportaciones de las y los profesionales de la red que colaboran con Loiolaetxea no dejan lugar a dudas al respecto: "sigue siendo un punto de referencia", "la persona se siente acogida y siente pertenencia", "cuando salen de Loiolaetxea, salen con una referencia casi para toda la vida" son algunas de las frases que lo atestiguan. Tampoco dejan lugar a dudas las voces de los residentes; veamos ésta, como ejemplo:

No se me cerró la puerta de Loiolaetxea, que siempre está abierta; si necesito algo o me pasa algo, puedo llamar: "mira, Marta, me pasa esto, tengo dificultades de [sic] hacer esto, me puedes echar un cable en esto" (R5: 38).

\subsection{Coordinados con el resto de profesionales de la red}

El tercer elemento necesario para que los procesos de inclusión se desarrollen adecuadamente hace referencia a la coordinación con el resto de los agentes que intervienen. Todas las personas transitamos por la vida. En este tránsito, en determinados momentos, por circunstancias diversas, hay personas que llegan a Loiolaetxea, a un lugar donde poder 'afrontar las heridas'. Quizá antes ya estuvieran en otros lugares y con otras personas, y seguramente después tengan que seguir en otros lugares y con otras personas. Ése es el fundamento y la clave de un proyecto que entiende que es un 'lugar en contacto con otros lugares'.

El objetivo de la coordinación no es sólo evitar duplicidades e incompatibilidades, como nos propone la Federación Sartu (2010), aunque esto sea importante. Tiene por finalidad fundamental garantizar un tipo de intervención respetuosa con la idea de totalidad del individuo. Consecuentemente, la coordinación permite facilitar una intervención integral con el sujeto, de forma tal que éste se sienta inmerso en una red de relaciones respetuosa con su proyecto vital. Pues bien, entre las opiniones analizadas encontramos que tanto los profesionales de atención primaria (sean del ámbito municipal o de Instituciones Penitenciarias) como los residentes perciben y estiman muy satisfactoria esta coordinación:

Luego, a nivel de coordinación, para mí sí será una de las entidades que mientras están en el centro mejor se coordinan o son más accesibles; quiero decir que yo he ido ahí, he visto el centro, ellos vienen. [...] Luego, la relación con los servicios sociales también es cercana, hay un feedback, desde mi punto de vista, positivo [...] Se negociaron los objetivos del trabajo a la salida tanto por la persona, como desde el centro, como desde servicios sociales (T3: 43).

N. juega después un papel de seguimiento, hasta que estoy, porque claro, cuando pasas de Portuenea a Loiolaetxea no es pasar y ya está, ¿no? Sí, N. tiene un seguimiento de cómo está siendo ese mes o mes y medio de J. en Loiolaetxea, cómo se ha adaptado, hay reuniones entre Marta, N. y yo, o sea, nos reunimos para hacer trasvases de cosas y para comentar pues cómo está siendo la adaptación de J. en su nuevo hábitat. Sí, sí, no hay un corte, N. sigue implicada; de hecho, yo con N. tengo conexión y ella es mi asistente nuevamente, puesto que estoy viviendo otra vez [en mi pueblo] ${ }^{2}$ (R4: 21).

Además de la coordinación de caso, Loiolaetxea pertenece a varias redes, entre ellas: Sargi; Hedatzen; la Red ESEM, de entidades del tercer sector que operan en prisión; la Red Harresiak Apurtuz; la Coordinadora de ONG de Euskadi de Apoyo a Inmigrantes; así como de la propia red de centros del sector social de la Compañía de Jesús.

\subsection{Utilizando los recursos normalizados existentes en el entorno}

Es evidente que cualquier proceso de inclusión debe atender dialógicamente tanto a los mecanismos de arraigo como a los de acceso. Estos últimos tienen que ver con la incorporación a la actividad económica y social, es decir, con el acceso al trabajo, con la estabilidad en los ingresos y con la protección, el acceso a la vivienda, la educación y la salud (Renes et al., 2007).

Como estamos viendo, Loiolaetxea trabaja los mecanismos de arraigo a partir de la generación de vínculos y de relaciones interpersonales que ayudan a superar las situaciones de soledad y falta de arraigo de quienes llegan a la casa. ¿Y todo lo demás? ¿Qué hacen las y los residentes? ¿A qué se dedican?

En los objetivos que se recogen en el PIA, hay cuestiones que tienen que ver con la regulación administrativa, con las causas penales pendientes, con la formación, con la ocupación y el empleo, con el ocio, o con el tiempo libre, la salud y la espiritualidad. Pues bien, en Loiolaetxea tratan de dar respuesta a estas cuestiones utilizando los recursos existentes en el entorno, aplicando así el principio de la normalización que recogía la Federación Sartu (2010).

Estudiar en la EPA, hacer un máster en Deusto, sacar el carné de conducir, acudir a un programa de desintoxicación, hacer la valoración de dependencia y empezar a trabajar en Gureak, ir a los talleres de

\footnotetext{
${ }^{2}$ Queremos hacer notar que nuestro interlocutor (J) habla sobre
} sí mismo en tercera persona. N. es su trabajadora social referente. 
Sartu, sacar la tarjeta Kirolgi que permite entrar en los polideportivos donostiarras, darse de alta en Lanbide, hacer el camino ignaciano con compañeros y compañeras de otras obras jesuitas, ser voluntario en Solidaritza -el grupo de profesoras y profesores del Colegio San Ignacio preocupados por cuestiones de cooperación internacional- o ir de cocinero a la ruta del camino de Santiago son las cosas que las y los residentes consultados han compartido de sus proyectos individualizados. Veámoslo con un ejemplo:

He tenido oportunidades de venir y estudiar y hacer un máster aquí, [...] a través de Loiolaetxea; que me facilitaron todo para estudiar; ahí te facilitan, te facilitan las cosas, si tú quieres hacer, pero desde que tú quieras, ¿no? Porque hay gente que no quiere, no quiere hacer. Yo creo que mayoría sí quiere, y además, tú tienes un periodo que tú económicamente, tú estás garantizado con cosas que tú [sic] no te tienes que preocupar: tú tienes dónde dormir y tal. Entonces, preocúpate en salir adelante y vinculando de ahí, pero sé autónomo, en ese sentido -y creo que las áreas que se trabaja[n] está[n] muy bien- en un sentido de que hace que tú cojas confianza de nuevo en ti, que puedas realmente hacer cosas que tú has pedido (R5: 16).

La utilización de los recursos normalizados, los que existen en el entorno, supone una manera de hacer efectivo el principio de ciudadanía, dado que la exclusión es, en parte, la imposibilidad de acceder a los espacios y recursos mejor valorados (Subirats, 2010).

\section{A partir de un modelo de trabajo, el modelo hogar}

Respecto a los mecanismos y formas de intervención, los teóricos de la exclusión nos recuerdan que estamos ante un fenómeno complejo y multidimensional (Laparra y Pérez Eransus, 2008) y que es necesario diseñar procesos de cambio que permitan a las personas pensarse de otro modo, imaginar su vida de otro modo (Federación Sartu, 2011). Asimismo, nos recuerdan que una mala intervención lo que puede hacer es pervertir la relación con el otro (Vidal Fernández, 2009).

Si, como nos decían Renes et al. (2007), para articular los procesos de reconstrucción y empoderamiento que se requieren para superar la ruptura del mecanismo de arraigo hay que generar y fortalecer espacios de apoyo enmarcados en procesos colectivos y en iniciativas singulares y donde la presencia del técnico se entiende desde su rol de acompañante, entonces es preciso establecer un marco donde ese acompañamiento tome cuerpo. En Loiolaetxea, ese marco es la vida cotidiana.

\subsection{Modelo hogar}

Etimológicamente, la palabra 'hogar' viene de 'hoguera', por tanto, produce sensaciones de calidez y calor. Cortina (2007: 38) nos recuerda que los seres humanos somos seres sociales y que nos reunimos con los demás; y que reforzar los vínculos familiares, la casa, la comunidad doméstica, "es central para cualquier ser humano y sobre todo para los jóvenes y los mayores, que son los grupos más débiles y vulnerables. La familia responsable sigue siendo una auténtica red de protección". La palabra que más veces han repetido todas las personas residentes consultadas es 'familia': Loiolaetxea es "mi familia”, es "mi casa", o mejor, "es la casa de todos":

Es mi familia, yo tengo una familia, entonces de decir no estoy sola, si me pasa algo, si viene la Policía y viene a por mí, yo tengo un montón de gente que está atrás y va a ayudarme. Y mira, esta persona vive aquí, tengo una dirección, tengo un sitio, tengo comida, vivo aquí; entonces no da esa sensación de desarraigo total (R5: 44).

La calidez que se percibe, por los gestos, los símbolos, los cuidados que Loiolaetxea entrega no sólo a los residentes, sino a todas las personas que tienen relación con ellos es uno de los elementos más destacados por las personas de las entidades que interactúan con ella:

Las personas necesitamos sentirnos respetadas, sentirnos escuchadas, recogidas. Qué importante, qué importante es ahí la atención de calidez, ¿no?, del afecto y demás. Y en esto, Loiolaetxea, pues son pioneros. Ese momento almuerzo, a las 11, el parón, el juntar al grupo. La percepción que uno tiene sobre cuál es el clima, ahí, ¿no?, el clima de unión, de recogimiento, de sentirse en familia (S4: 36).

Un modelo que también tiene sus riesgos; riesgos que se ven desde el exterior, que aportan las voces de las personas de las entidades que se preguntan si una intensidad de relación tan grande no puede generar dependencia. Son aportaciones que se dejan sin concretar y que se hacen desde un punto de vista más teórico o de posibilidad que práctico y de realidad. En este sentido, las y los residentes hablan de valores como "respetar y ser respetado", “acompañar al compañero", "fomentar la autonomía y el empoderamiento”, “convivencia”, no juzgar”, "apoyo incondicional”, "libertad y seguridad”. Refieren la dificultad de tener que marcharse, pero entienden que la marcha es un paso más en su proceso de avanzar hacia mayores cotas de autonomía.

\subsection{Modelo comunitario}

El modelo hogar del que hemos hablado en el apartado anterior tiene su razón de ser en una de las características singulares de Loiolaetxea: la 
presencia de una comunidad de vida compuesta por jesuitas que conviven en la misma casa. Así se expresa una de las participantes en esta investigación:

Un hecho diferencial, para mí, que es positivo, es, por ejemplo, bueno, pues que haya en la casa siempre una presencia permanente de una comunidad religiosa (S1: 66).

El proyecto de Loiolaetxea nació a partir de la imbricación de dos ideas: la primera tiene que ver con la creación de 'experiencias de vida en común', comunidades de vida en las que viven y conviven (algunos habitando en la casa y otros sin que convivan bajo el mismo techo) jesuitas, laicos y laicas, religiosos y religiosas de otras órdenes, junto a personas con experiencia penitenciaria 0 en exclusión social; y la segunda hace referencia a la opción de Loiolaetxea de ser ante todo una 'comunidad de solidaridad inclusiva', una comunidad de vida que permita el crecimiento y desarrollo personal de quienes vivan en ella.

Obviamente, no se puede ocultar en ambas ideas la fundamentación religiosa que las sustenta (recordemos que el proyecto está inspirado en un modelo de vida ignaciano). Sin embargo, lo determinante es que se trata de una cosmovisión religiosa que es, al mismo tiempo, afirmadora de un desarrollo individual perfectamente coherente con los objetivos de una política social integradora. Dicho de otro modo, la opción religiosa que sustenta Loiolaetxea no vulnera para nada ni en el orden doctrinal, ni en el relacional, una opción amplia, abierta, integradora y técnica del problema.

Además, la presencia de la comunidad da consistencia al proyecto, le otorga 'familiaridad', dado que siempre hay alguien dispuesto a escuchar, a conversar, a dialogar, a confrontar. Consecuentemente, acentúa la dimensión relacional necesaria en individuos cuyo itinerario vital está lleno de desencuentros, desarraigos y rupturas. Dicho de otra forma, el afianzamiento de la dimensión relacional acentúa el grado de estabilidad y autoconfianza, tan necesarios para poder reiniciar y ganar autonomía:

¡Jo!, aporta muchísimo, porque estás acompañado durante todo el día: quieres hablar, quieres cualquier cosa, te puedes tomar un café, hay roce, hay cariño. Y yo creo que son..., es esencia en esa casa el que estén ellos ahí, es esencia, porque estás impregnado, en un momento dado estás impregnado de ese espíritu que ellos llevan, y esas cosas (R4: 11).

No debemos olvidar que las personas que acuden a Loiolaetxea conocen esta circunstancia, dado que hay un trabajo previo de conocimiento mutuo. Además, no es el único centro que atiende a este colectivo, por lo que aquellas personas que no consideraran un valor su presencia han podido ser derivadas a otros centros. Así lo expresa el técnico de una entidad que trabaja dentro de la prisión de Martutene:

Entonces, cuando al final va a Loiolaetxea, ya sabe a dónde va, ya se le ha explicado todo. Ahí puede haber personas, no es lo habitual, pero sí ha habido algún caso que yo he atendido, que al ver el grupo, el confrontar en grupo, el participar en grupo, pues no han querido. [...] Y acabó yendo a pisos de Cruz Roja. Pues porque, bueno, era una persona que llevaba muchos años en prisión, muchos años institucionalizada y no aceptaba esa, esa convivencia grupal. Cosa que en una casa de Cruz Roja, claro que convives, pero el nivel de exigencia en la convivencia, o el nivel de implicación, de intensidad, es menor $\left(\mathrm{S}_{5}: 6\right)$.

En cualquier caso, no podemos obviar en este punto, entre otros, el conflicto derivado entre la visión institucional del problema, su necesidad de codificación y de regulación (la Cartera de Servicios y Prestaciones del Sistema Vasco de Servicios Sociales) con la peculiaridad y particularidad de experiencias como la de Loiolaetxea. Aquí topamos con los límites del sistema, con el conflicto entre la necesidad de sistematización y particularización de la oferta de servicios. En estos límites surgen, a veces, desconfianzas, temores y, ¿por qué no decirlo?, recelos institucionales derivados de la orientación ideológica de los diferentes proyectos. De este modo, el binomio universalidad-particularismo suele aparecer con gran fuerza. En el caso que nos ocupa, las reticencias se derivan de la vinculación del servicio de Loiolaetxea con la Cartera; es decir, hay personas tanto del entorno del conocimiento como de las entidades que entienden que la aportación de valor que presenta la comunidad de vida de Loiolaetxea es algo que no puede estar recogido en la Cartera y que, por tanto, hay que identificar claramente para evitar confusiones. Para muestra de lo que decimos, la siguiente cita:

En la Cartera, no puede estar que seas una comunidad y que tú vivas y que el valor añadido de Loiolaetxea si es ése, si yo tengo razón y es ése, eso en la Cartera no está. [...] Ese servicio residencial va a tener todos esos servicios los preste quien los preste, va a tener equis características del servicio, de copago, de perfiles, de ratios, de reglamentos. Si tú ahora además a eso, prestando eso, le das un valor añadido más, pues tiene sentido ( $\left.C_{3}: 81\right)$.

En cualquier caso, la apuesta jesuita por una comunidad de vida quiere destacar, para negar, una de las claves de la exclusión, el pensamiento de que no es posible vivir con personas en situación de exclusión:

La dimensión simbólica creo que ha sido siempre la gran aportación de Loiolaetxea a los modelos de la red. Esa dimensión simbólica tiene que ver con que es mentira que no se puede vivir con las personas en procesos de exclusión, y por eso están 
excluidas. Eso es mentira, es falso, llevamos quince años viviendo juntas $y$, bueno, pues podremos decir si es fácil o difícil, si es complejo, pero la afirmación que podemos hacer después de quince años es que la exclusión no responde a un patrón de personas que quieren vivir aisladas o que no pueden vivir en comunidad o en sociedad (L2: 23).

\subsection{Abierto}

El modelo comunitario de solidaridad inclusiva parte de la idea de que, para la inclusión, no es suficiente con que las personas que están en riesgo o situación de exclusión quieran salir de esa situación, sino que es imprescindible que la sociedad dé un paso al frente y asuma también su compromiso de "hacer sitio'. Cabe recordar que, precisamente esta idea de movimiento bidireccional es lo que se argumenta para diferenciar conceptualmente términos como inserción o inclusión (Aguilar, Gaviria y Laparra, 1995; SIIS Centro de Documentación y Estudios, 2012). Para ello, es indispensable dar a conocer la realidad de las personas concretas a la ciudadanía, para que ésta se sensibilice. Y por tanto, hay que tener una casa abierta, acogedora:

Cómo podemos incidir en esa ciudadanía, que nos conozca, que nos conozcamos a través de algún proyecto pequeñito que genere sensibilización, y bueno, pues que nos quite esas imágenes peyorativas que a veces tenemos de algunas personas. Pues, por ejemplo, con el proyecto de la huerta3 $^{3}$ (L3: 63).

Loiolaetxea es una casa abierta. Cualquier día puede aparecer a comer algún acompañante de cualquiera de las personas que conviven en ella. $Y$ esto es agradable y positivo para casi todas las residentes consultadas cuando se les pregunta por la cuestión:

Pues a mí, a mí me encanta eso. Porque yo, primero con los niños, yo he estado con los niños en la huerta y, sí, desde primero y me encantó la actividad, con los niños me encantó, y también la gente que viene de fuera (R3: 27).

Sólo una persona señala que el hecho de que sea tan abierta y de que pase mucha gente en cualquier momento le provoca cierta dificultad. La justifica aludiendo a cuestiones relacionadas con la salvaguarda de la intimidad y el sentimiento de posesión:

[Y eso de que la casa sea tan abierta] a veces me molestaba, porque a veces sentía necesidad de tener un poco más de privacidad. Entiendo también, por otro lado, que tiene que ser así, pero sí me molestaba. También el concepto ese,

3 Loiolaetxea tiene un jardín con una pequeña huerta. Actualmente tienen un proyecto de colaboración con alumnos de primero y segundo de primaria en el que, por grupos, vienen a cuidarla junto con un monitor y residentes voluntarios. es mío, mi espacio, mi casa, es mío, no quiero compartir... (R5: 28).

\subsection{Donde hay profesionales y voluntarios}

Uno de los factores clave en cualquier sistema de atención es la profesionalización de la intervención. Sin embargo, esta cuestión quizá ha llegado más tarde al ámbito de la inclusión que a otros como infancia, mayores o discapacidad. Así lo expresaba una de las voces participantes:

Los servicios vinculados a exclusión no se han atendido tanto, no se han visto tanto vinculados a la profesionalización de los servicios sociales. Parece que en exclusión, con todo el respeto del mundo, puede trabajar cualquiera y se pueden nutrir de voluntarios (P4: 5).

La profesionalización de Loiolaetxea genera en el resto de la red gran confianza, sobre todo en aquellos que asumen la responsabilidad de la derivación de las personas al centro, como puede ser la Diputación Foral o Instituciones Penitenciarias, en tanto consideran que sirve como referente para poder otorgar permisos penitenciarios a aquellos reclusos que, habiendo cumplido los requisitos, no tienen familia o lugar de residencia. Una confianza que se traduce en tener 'un lenguaje común' y ‘espacios de coordinación’, y que emana de la consideración muy positiva hacia los profesionales de Loiolaetxea. Una consideración positiva que comparten las personas residentes que califican a las y los profesionales como competentes y de una calidad humana significativa:

Para mí, Loiolaetxea, es que tienes el equipo técnico ahí; eso es un lujazo, un equipo técnico como ése, además con esa calidad humana y profesional de gente que, bueno, que se les ve que les gusta, tienen unos valores que los transmiten, que se preocupan por ti. Bueno, para mí, el equipo técnico que tienen es muy bueno, saben de dónde venimos, saben qué tipo, qué habilidades tienen que utilizar y cómo tienen que tratarlas, tienen muchísima paciencia también (R2: 24).

La opción por la profesionalización fue adoptada por la propia Loiolaetxea allá por 2004, porque le permitía escalar en el acompañamiento a las personas derivadas desde prisión, aumentando el número de personas atendidas. Además, supuso poner en relación las herramientas técnicas que aportaban las y los profesionales y las experiencias comunitarias de la comunidad de vida. Así lo cuenta una de las personas de Loiolaetxea, resumiendo lo que todos comparten:

Porque sí que se ven limitaciones desde la parte exclusivamente comunitaria: no se podían acompañar, o sea solamente, digo; con esa parte de vivir, había algo más que en ese momento se 
dieron cuenta que necesitaban, y a ese nivel es cuando se incorpora la parte más profesional, más de intervención (L3: 8).

Profesionales que están acompañados por voluntarias y voluntarios que asumen tareas complementarias de acompañamiento y apoyo puntual. Un voluntariado que sigue teniendo su papel y que está reconocido desde cualquier esfera: el ámbito público, el del conocimiento y el de las entidades, además, claro está, de la propia Loiolaetxea y de las personas que residen allí.

La opción por un modelo comunitario y abierto donde quepan personas con distintas funciones y roles es fundamental para avanzar en la transformación social. En la sociedad relacional en la que estamos inmersos, posibilitar que personas distintas se conozcan, colaboren y se acompañen mutuamente es una de las estrategias que ayudarán a tejer otras relaciones consistentes que superen las relaciones líquidas que parecen caracterizar nuestro tiempo.

\section{Desde una opción cristiana por vincular fe y justicia}

En la literatura especializada, encontramos innumerables estudios que refieren que la dimensión espiritual (que no religiosa) es una de las dimensiones constitutivas del ser humano, junto con las dimensiones biológica, social, cognitiva y psíquica-emocional. Se le suele denominar dimensión espiritual o transcendental o de sentido de la vida. Buscar un sentido a la vida es fundamental para vivir una "vida buena" (Paul Ricoeur); sin embargo, es clave también en cualquier episodio o proceso de sufrimiento. Así lo expresó Viktor E. Frankl ([1946] 1991: 64):

Uno de los postulados básicos de la logoterapia estriba en que el interés principal del hombre no es encontrar el placer, o evitar el dolor, sino encontrarle un sentido a la vida, razón por la cual el hombre está dispuesto incluso a sufrir a condición de que ese sufrimiento tenga un sentido.

El abordaje de la dimensión espiritual es una de las aportaciones singulares que hace Loiolaetxea a la red de atención en el ámbito de la inclusión social en Gipuzkoa.

Como sabemos, Loiolaetxea es una obra de la Compañía de Jesús de la que recibe misión y con la que comparte carisma. La Compañía de Jesús tiene como misión "defender la fe y promocionar la justicia” a la que están llamados todos los jesuitas y todas las obras. Esta misión se concreta en acciones tendentes a la promoción de la justicia, el acompañamiento a personas y grupos en la búsqueda de sentido e interiorización; el anuncio y celebración de la fe; y el estar en las fronteras, desde el diálogo y la reconciliación. Concretamente, y en lo relativo a la opción que hace referencia explícita al acompañamiento, servicio y defensa de los pobres y excluidos como exigencia de la fe, la Compañía, recogiendo lo que la Congregación General 35 anunciaba, formula la opción por los pobres de esta manera:

Nuestro compromiso de ayudar a establecer relaciones justas nos invita a mirar el mundo desde la perspectiva de los pobres y marginados, aprendiendo de ellos, actuando con ellos y a su favor. [...] Con una llamada profética (el Santo Padre) nos invita a renovar nuestra misión "entre los pobres y con los pobres" CG 35, D.3, n- 27 (Jesuitak-Loiola Probintzia, 2010: 19).

En Loiolaetxea, esta opción se hace vida. La comunidad de jesuitas que vive ahí abre su casa para acoger a personas en riesgo o situación de exclusión, para aprender de ellas y acompañarse mutuamente. Constituyen una comunidad única, en donde las personas que la integran asumen distintos roles, funciones, carismas y situaciones personales. Todas ellas comparten un mismo motivo, la experiencia de la inclusión, y un mismo presupuesto: todas y todos los que participan de esta experiencia pueden dar y recibir.

Desde la administración pública, se considera que la identidad religiosa de Loiolaetxea no es un factor que invalide ni dificulte su presencia en la red de atención. Se considera que la comunidad es "abierta en el terreno religioso", "integradora", "no proselitista", "rica” y sobre todo "muy respetuosa”, valores compartidos por todas las personas consultadas, independientemente de su adscripción política.

Somos conscientes de que, en el momento actual, una ética cívica emergente está cuestionando sistemáticamente este tipo de iniciativas vinculadas a determinada adscripción religiosa. Nada de esto se ha visto reflejado en las entrevistas realizadas al hablar de Loiolaetxea. Su carácter abierto y de diversidad de prácticas religiosas, muy respetuoso con las personas independientemente de sus creencias, le otorga también una presencia y legitimidad clave en la red. Incluso hay aportaciones de voces de la administración pública de diverso signo político que destacan la importancia de que en la red existan centros que tengan en cuenta la dimensión espiritual para poder entender y atender mejor a ese grupo de creyentes de distintas confesiones, haciendo explícito el derecho de conciencia de las personas:

¿Qué pasa con personas que acuden a centros que tienen creencias religiosas o culturales diversas y el respeto a esas creencias culturales o religiosas? Sí que creo que es importante ser escrupulosos, ¿no?, por el respeto a las diferentes ideologías y creencias de las personas, y por lo tanto, igual que Loiolaetxea pueda ser una organización de jesuitas, y fenomenal, que sean lo que quieran, pero de la misma manera, facilitar 
que las personas que acudan a este servicio que puedan ser de otras religiones o ateas, como yo, pues que no se sientan presionadas de ninguna forma. Porque hay muchas cuestiones que parece que son culturales, pero que tienen un trasfondo religioso y que, bueno, yo creo que hay que trabajar y pensar y reflexionar mucho ( $\left.\mathrm{P}_{2}: 99\right)$.

Loiolaetxea distingue claramente entre espiritualidad y confesionalidad, y opta por trabajar la dimensión espiritual de las personas desde la óptica del diálogo interreligioso y la diversidad de espiritualidades. Esto es lo que constituye su activo más preciado:

Promovemos una ciudadanía con espíritu, porque cuidar en la persona dimensiones como la de la espiritualidad más allá de la confesionalidad, es decir, de ámbitos donde se pueda expresar en su interioridad, con gente que no son cristianos o que algunos claramente son musulmanes y llevan sus prácticas, y vivirlo con una apertura y con normalidad, supone un planteárselo, renunciar también a algunas formas personales de expresión, que me parece que es un elemento que falta en la sociedad y que va a ser muy necesario. Es decir, al final hablamos mucho de, bueno, hablamos, o está todo el debate de la interculturalidad y del diálogo interreligioso. Yo creo que vamos perdiendo un poco el miedo a hablar para decir, bueno, una espiritualidad laica, aunque no se llame así, bueno cada uno tiene la que tiene y la pone sobre la mesa, ¿no? Y yo creo que cultivar esas dimensiones es importante, y más en procesos donde el fracaso está tan presente (L4: 43).

Algunas de las personas consultadas consideran que esta opción se plasma y se visualiza en el modelo de cuidados y en las opciones de Loiolaetxea. Una vez más, encontramos voces que vuelven a cuestionar si un servicio que pertenece a la red pública puede tener una ideología tan concreta, ya que entienden que la ideología siempre impregna la actuación de cada cual. Sin embargo, no se tiene en cuenta que toda persona e institución tiene de facto una ideología, y que toda intervención responde a determinadas creencias y supuestos teóricos, por lo que habría que matizar esta cuestión e iniciar un diálogo sobre cómo inciden las ideologías en los procesos de intervención.

En cualquier caso, las y los profesionales que interactúan con Loiolaetxea señalan que no han coincidido con personas que, habiendo vivido allí, hayan manifestado haberse sentido coaccionadas por la comunidad ni por las creencias ahí manifestadas. Aunque, ciertamente, en esa fase de conocimiento mutuo que se da antes de la entrada a la casa, es un elemento que se valora, por lo que aquellas personas que pudieran sentirse incómodas con la opción de fe o la dimensión espiritual se derivan a otros centros.

Entre las personas residentes consultadas dos son musulmanas, una budista y dos católicas. Todas, sin excepción, estiman muy satisfactoria la experiencia de poder abordar la dimensión espiritual, dado que consideran que es un elemento valioso de su identidad. Las personas que profesan religiones distintas a la católica no se esperaban encontrar el grado de respeto, apertura y diálogo con el que se trata la cuestión de la espiritualidad. Incluso alguna manifiesta la preocupación que le suscitó antes de entrar a Loiolaetxea:

Al principio, no, pensaba que era un poco secta y “¿yo me voy a meter aquí con todos estos católicos?”. Yo tenía mucha mala experiencia en Brasil con el tema de la religión, porque antes de ser budista, de considerarme budista, he pasado por todas las religiones que te puedes imaginar, y claro, yo pensaba que esto iba a ser un lavado de cerebro. Pero bueno, esto es mejor que la cárcel, así que me voy, aquí no me quedo. No, para nada esperaba que fueran a respetar y tampoco esperaba encontrar la diversidad de personas que hay participando en proyectos. Te sientes acogida también porque, aunque no compartan tu fe, ellos valoran que tú tengas una y entienden que tú tienes que tener tu espacio para trabajar eso. Sí, además Manu muchas veces participa, me decía: “¿puedo ir?”, “¿vamos juntos?”, “¿puedo hacer?” (R5: 21).

Las entrevistas a las y los residentes se efectuaron durante la celebración del Ramadán. El hecho de poder celebrarlo, de poder hacer las prácticas religiosas asociadas tal y como las habían aprendido, de que eso no supusiera ningún problema (aun siendo conscientes del trastorno que suponen para la vida de la casa), y de que incluso el responsable jesuita del proyecto lo realizara también con ellos es uno de los elementos más valorados de la estancia en Loiolaetxea:

Esa experiencia la verdad la he vivido muy bien, por lo cual lo que esperaba no era así, porque yo pensaba que iba a ser un poco difícil para mí, que lo que pensaba que iba a ser más difícil para poder cumplir mi religión o cumplir este tipo de cosas, ahí cuando llega el Ramadán, por ejemplo. Esto, la verdad, me acordaba si fuera también, si estoy en mi familia, porque no notaba nada de cómo hay separación (R1: 18).

Ésta es la opción de la Compañía, una opción constitutiva y primigenia, estar en la "realidad real":

Al final, es estar en un sitio donde sentimos que hay una llamada por situaciones de injusticia, marginación, y la Compañía tiene esa sensibilidad de decir: tenéis que estar ahí donde se dan problemas y dramas humanos hoy, y hay que estar, como comunidad, ciertamente, estar con una espiritualidad (L4: 39). 


\section{Con retos particulares derivados de su propia singularidad}

Como entidad de iniciativa social, a Loiolaetxea le afectan los retos identificados en el conjunto del tercer sector: la necesidad de ubicarse en un nuevo contexto social; la importancia de mejorar el servicio; y la exigencia moral de seguir demostrando que 'otro mundo es posible' a partir de fundamentos como la solidaridad inclusiva, la hospitalidad y la interculturalidad y el diálogo interreligioso. Sin embargo, su propia singularidad, su especificidad le generan retos particulares, cuestiones que quizá no están suficientemente bien contempladas o sea necesario tener presentes para reflexionar sobre ellas y valorar si es preciso adoptar decisiones que mejoren el servicio.

\subsection{En cuanto a las condiciones estructurales de Loiolaetxea}

Como señalábamos al inicio de este artículo, el proyecto está ubicado en una villa de tres plantas con escaleras interiores. Las habitaciones son individuales y el baño se comparte. ¿Cómo afectaría una hipotética regulación de los espacios como la que hay en otros sectores (en menores, por ejemplo)? La incorporación de medidas derivadas de las normativas de accesibilidad arquitectónica, por ejemplo, podrían suponer la necesidad de revisar y repensar su disposición. En este sentido, reiteramos nuestra opinión sobre la necesidad de valorar in situ las condiciones estructurales de Loiolaetxea y considerar los beneficios que ésta ofrece.

\subsection{En cuanto a la opción por atender las situaciones no contempladas en la Cartera}

Una de las singularidades de las entidades sociales, aquello que además les ha otorgado identidad y legitimidad, es haber atendido a personas en situaciones no asumidas por la propia Administración. Es desde esta clave desde donde Loiolaetxea opta por asumir con sus propios fondos un número de plazas (concretamente tres) para poder tener sitio disponible ante cualquier eventualidad derivada de la propia idiosincrasia del funcionamiento de Instituciones Penitenciarias.

Los permisos solicitados por las personas presas para acudir a Loiolaetxea pueden concederse de la noche a la mañana, impidiendo o dificultando la entrada por los canales habituales. A veces, son permisos muy cortos en el tiempo (un fin de semana), que 'rompen' con el itinerario de acceso diseñado por la Diputación. Como apuntábamos anteriormente, hay voces del ámbito foral que consideran esta cuestión como uno de los retos en el abordaje de la atención al colectivo preso, siendo además, uno de los elementos de fricción entre ambas instituciones.
En este sentido, entendemos que Loiolaetxea debe seguir asumiendo la función de mediación entre la Diputación e Instituciones Penitenciarias, ayudando a allanar el camino entre estas dos administraciones (foral y estatal), distintas y poco conectadas en la actualidad.

\subsection{En cuanto a su modelo de intervención}

Como suele ocurrir en la vida, a veces las fortalezas de una entidad pueden convertirse en su propia debilidad.

En primer lugar, Loiolaetxea trabaja el arraigo a partir de un modelo de intervención sustentado en la generación de vínculos estrechos con las y los residentes, lo que hace que la propuesta de acompañamiento que les presentan sea envolvente y muy intensa. Éste es un factor conocido y muy valorado por la red, de forma que las personas que tienen responsabilidades en la derivación saben que Loiolaetxea tiene unas condiciones determinadas y que no sirve para todas las personas: hay quien no quiere o no necesita ser acompañado tan estrechamente, que no quiere o no puede con un plan de seguimiento y acompañamiento de corte grupal y comunitario.

A veces, las y los residentes perciben esa dificultad cuando ya están en el proyecto. Otras veces, viven la estancia en el proyecto como la única alternativa para salir de prisión, por lo que esta circunstancia puede surgir en la propia dinámica cotidiana. Sea como fuere, todas y todos deberían ser conscientes de esta situación: la red, cuando deriva; y el equipo de Loiolaetxea, cuando se generan los conflictos relacionados en la vida cotidiana.

Esta consideración no puede afectar al principio de equidad. Hemos escuchado voces que cuestionan que las entidades puedan tener cierto grado de decisión al aceptar o no a las personas derivadas, en razón de la dinámica concreta y particular del grupo que convive en ese momento en el proyecto. Ubicamos la aportación anterior en el marco del principio general de adecuar el recurso a la persona, y no viceversa. Somos conscientes de que este principio está aceptado unánimemente por la red. Sin embargo, dado que las particularidades de las personas son muchas y los servicios de la red limitados, no siempre es posible su aplicación.

En segundo lugar, Loiolaetxea trabaja el arraigo desde la implicación personal de una comunidad de vida y un equipo de profesionales que se 'contagian' de ella. La conjunción de estas dos propuestas u opciones vitales puede tener también varias sombras que es preciso contemplar.

Loiolaetxea tiene que ser consciente (seguramente ya lo es, dada la poca rotación de profesionales que existe en ella) de que debe acompasar distintos grados de implicación en las personas de sus 
equipos. No es lo mismo la opción de vida de un jesuita que la de una profesional que entiende su estancia y participación en el equipo desde un prisma profesional. Ambos son legítimos, complementarios y necesarios en Loiolaetxea, sin embargo consideramos que ello pudiera generar fricciones, por lo que este asunto debería tomarse en cuenta y abordarse. Ciertamente, el hecho de que tenga espacios para la supervisión del equipo da cuenta del grado de conciencia que tiene en relación con la necesidad de articular espacios de comunicación y abordaje de conflictos entre profesionales. 
AGUILAR, M.; GAVIRIA, M.; y LAPARRA, M. (1995): La caña y el pez, Madrid, Fundación Foessa.

CÁRITAS ESPAÑOLA (2009): Marco de intervención con personas en grave situación de exclusión social, Madrid, Cáritas Española.

CORTINA, A. (2007): “Jóvenes, valores y sociedad siglo XXI”, Proyecto. Revista Trimestral de la Asociación Proyecto Hombre, no 63, págs. 27-38. [<http:// www.proyectohombre.es/archivos/19.pdf>].

FEDERACIÓN SARTU (2011): Estrategias profesionales para la inclusión social, Federación Sartu [<http:// www.siis.net/es/documentacion/catalogo/ Record/183852>].

- (2010): Tendencias sociales e inclusión social, Federación Sartu.

FRANKL, V. [1946] (1991): El hombre en busca de sentido, Barcelona, Herder.

JESUITAK-LOIOLA PROBINTZIA (2010): Proyecto de provincia. Texto de misión y líneas estratégicas 20092014.

LAPARRA, M.; y PÉREZ ERANSUS, B. (coords.) (2008): Exclusión social en España. Un espacio diverso y disperso en intensa transformación, Madrid, Fundación Foessa.

RENES, V. et al. (2007): “Realidad, pensamiento e intervención social”, Documentación Social, nํㅜ 145, págs. 11-35.

SCHÖN, D. (1998): El profesional reflexivo. Cómo piensan los profesionales cuando actúan, Barcelona, Paidós.

SIIS CENTRO DE DOCUMENTACIÓN Y ESTUDIOS (2012): Activación y derecho a la inclusión en el marco de las políticas de empleo y de garantía de ingresos en la CAPV / Aktibazioa eta gizarteratzako eskubidea, EAEko enpleguko eta diru-sarrerak bermatzeko politiken esparruan, Vitoria-Gasteiz, Eusko Jaurlaritza-Gobierno Vasco [<http://www.siis.net/es/investigacion/ ver-estudio/372/>].

SUBIRATS, J. (2010): Ciudadanía e inclusión social: el tercer sector y las políticas públicas de acción social, Prat de Llobregat, Fundación Esplai.

VIDAL FERNÁNDEZ, F. (2009): Pan y rosas. Fundamentos de la exclusión social y el empoderamiento, Madrid, Fundación Foessa; Cáritas Española. 